\title{
Chemical Constituents of Snake Fruit (Salacca zalacca (Gaert.) Voss) Peel and in silico Anti-aging Analysis
}

\author{
Ermi Girsang ${ }^{1}$, I Nyoman Ehrich Lister ${ }^{1}$, Chrismis Novalinda Ginting ${ }^{1}$, Adrian Khu ${ }^{1}$, Butter Samin ${ }^{1}$, \\ Wahyu Widowati², Satrio Wibowo ${ }^{3}$, Rizal Rizal ${ }^{3}$ \\ ${ }^{1}$ Universitas Prima Indonesia, Medan, Indonesia \\ ${ }^{2}$ Medical Research Center, Faculty of Medicine, Maranatha Christian University, Bandung, Indonesia \\ ${ }^{3}$ Biomolecular and Biomedical Research Center, Aretha Medika Utama, Bandung, Indonesia
}

Background: Skin aging is a condition where skin is unable to retain both its physiological and structural integrity. Plants is the main source of phtytochemicals compound with wide range of biological activities. Through the efforts of ongoing scientific researches, an increasing number of plant extracts and phytochemicals have been showed promising result as anti-aging agent. Snake fruit (Salacca zalacca (Gaert.) Voss) is tropical plant belongs to the palm tree family (Arecaceae) that served as important crop in Indonesia. Despite its utilization, the phytochemical compound available in snake fruit, especially its peel have not been well documented. Present study aimed to elucidate the phytochemical constituent of snake fruit peel and its anti-aging potency.

Materials and Methods: Snake fruit peel extract (SPE) was subjected to qualitative phytochemical assay, high performance liquid chromatography, and molecular docking towards protein related in skin aging.

Results: The screening showed SPE contained phytochemical compound belong to flavonoid, tannin, phenol, triterpenoid, saponin and alkaloid. Thus, based on the analysis only chlorogenic acid was present in SPE whilst rutin and caffeic acid were not detected. The SPE was contained chlorogenic acid around $1.074 \mathrm{mg} / \mathrm{g}$ dry weight. Chlorogenic acid had the high binding affinity towards matrix metalloproteinase (MMP)-1 (-9.4 kcal/mol).

Conclusion: Current findings may provide scientific evidence for possible usage of SPE and its compounds as antioxidant and anti-aging agent.

Keywords: Salacca zalacca, phytochemical compound, high performance liquid chromatography, anti-aging

\section{Introduction}

Skin aging is a condition where skin is unable to retain both its physiological and structural integrity. ${ }^{1}$ There is numbers of factors that contribute to the pace of skin aging. ${ }^{2}$
Harmful environmental stimulus such as ultraviolet (UV) and free radicals plays role as external skin aging factors. These factors involved with wide-range of pathway through the changes of reactive oxygen species (ROS) level in the body. The imbalance between the production of ROS and

Date of submission: March 28, 2019

Last Revised: May 14, 2019

Accepted for publication: May 20, 2019

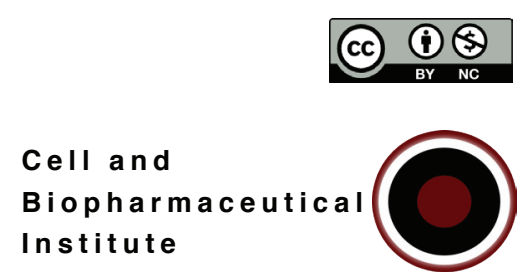

Corresponding Author:

Ermi Girsang

Faculty of Medicine, Universitas Prima Indonesia

Jl. Belanga No.1, Sei Putih Tengah, Medan 20118, Indonesia

e-mail: ermigirsang@unprimdn.ac.id 
its elimination often found in aged skin, whereas condition known as oxidative stress. ${ }^{3}$ The structural protein constructed the skin connective tissue were subjected to degradation in aged skin, as the result of up-regulation of several types of collagenases and elastases. In vivo study showed the up-regulation skin fibroblast elastase was regulated by the formation of oxidative stress. Radical compound is also able to activate a series of signaling pathway that leads to the apoptosis of skin fibroblast. ${ }^{4}$ Combined, both process resulted in the diminishment of skins cellular integrity. The inhibition of radicals was become important approach for treating skin aging.

Phytochemical compound is group of chemical found in plants with wide-range of beneficial biologcal activities. ${ }^{5}$ These biological activities underlies the medicinal usage of plants or herbal medicine. Important groups of phytochemical compound including phenol and flavonoid are the responsible for the most of beneficial activities that plant extract have..$^{6-8}$ Ever increasing scientific researches expand our knowledge for the promising plant extracts and phytochemical as anti-aging agent. ${ }^{9,10}$ Thus characterization phytochemical compound constituent in plants served as important step towards its empirical medicinal utilization.

Snake fruit (Salacca zalacca (Gaert.) Voss) is a species of palm tree family (Arecaceae) originated from Indoneisa. Snake fruit considered as important crop since it have high economic value and had been cultivated throughout Indonesia. The fruit consisted of edible pulp which considered a delicacy, and inedible peel which become the main waste of snake fruit consumption. Despite its utilization,the phytochemical compound available in snake fruit, especially its peel have not been well documented. To address this snake fruit peel extract (SPE) was subjected to qualitative phytochemical assay, high performance liquid chromatography, and molecular docking towards protein related in skin aging.

\section{Materials and methods}

\section{Preparation of Plant Extracts}

The plant material was collected from Bogor, West Java, Indonesia. The plant material was then identified by the herbarium staff of Biology Department, School of Life Sciences and Technology, Bandung Institute of Technology, Bandung. The snake fruit peel was cleaned, dried, and ground into fine powder. Dried snake fruit peel powder was then macerated in distilled ethanol (70\%). After $3 \times 24 \mathrm{~h}$ the extract was passed through filter and obtained filtrate was evaporated at $40^{\circ} \mathrm{C}$ until became paste. The SPE was then diluted with dimethyl sulfoxide (DMSO) (Catalogue \#D8418, Sigma Aldrich, Missouri, USA). ${ }^{9-11}$

\section{Qualitative Phytochemical Screening}

The phytochemical assay was conducted on SPE using modified Farnsworth method to qualitatively identify presence of phenol, steroid/triterpenoid, saponin, tannin, terpenoid, flavonoid, and alkaloid as listed below. ${ }^{9-11}$

\section{Phenolic Compound Identification}

Ten $\mathrm{mg}$ of SPE was dissolved in $5 \mathrm{~mL} \mathrm{ddH}_{2} \mathrm{O}$ in a test tube and mixed with $500 \mu \mathrm{L} \mathrm{FeCl}_{3}$ solutions (Catalogue \#1.03861.0250, Merck, Darmstadt, Germany). The presence of violet colour indicates the presence of phenolic

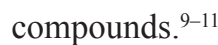

\section{Tanin Identification}

Solutions consisted of $10 \mathrm{mg}$ SPE in $2 \mathrm{~mL}, 2 \mathrm{~N} \mathrm{HCl}$ (Catalogue \#1003171000, Merck) was heated up in waterbath for 30 minutes. After it cooled down, $500 \mu \mathrm{L}$ amyl alcohol (Catalogue \#10979, Merck). was then added. As the mixture turns red or orange, compound belong to tannin was present on the plant sample. ${ }^{9-11}$

\section{Flavonoid Identification}

Ten mg SPE was dissolved in $2 \mathrm{~N} \mathrm{HCl}$ in a test tube followed by addition of $\mathrm{Mg}$ (Catalogue \#EM10581, Merck). The mixture was heated and filtered after it cooled down. Amyl alcohol was then added into the filtrate. The presence of flavonoid in sample indicated by the formation of red or orange colour. ${ }^{9-11}$

\section{Alkaloid Identification}

Briefly, $10 \mathrm{mg}$ of dissolved SPE in $5 \mathrm{~mL} \mathrm{ddH}_{2} \mathrm{O}$ was heated using water-bath. The residue produced was dissolved in 5 $\mathrm{mL}, 2 \mathrm{~N} \mathrm{HCl}$ and divide into two different test tube. The first test tube was added $2 \mathrm{~N} \mathrm{HCl}$ and used as colorless reagent blanks. The dragendorff reagent ( 3 drops) was then added to the second test tube. The formation of yellow sediment indicates the presence of alkaloid in the plant sample. ${ }^{9-11}$

\section{Saponin Identification}

Ten $\mathrm{mg}$ of SPE was dissolved in $\mathrm{ddH}_{2} \mathrm{O}$ in a test tube and boiled for 5 minutes. The solution was filtered and obtained filtrate was shook vigorously. $\mathrm{HCl}$ was then added into the solution. The persistence of froth on the solution surface indicates the presence of saponin in plant sample..$^{9-11}$ 


\section{Steroid/Triterpenoid Identification}

Ten $\mathrm{mg}$ of SPE was added galical acetate acid $\left(\mathrm{CH}_{3} \mathrm{COOH}\right)$ in a spot plate and was incubated for 10 to 15 minutes. One drop of absolute sulfate acid $\left(\mathrm{H}_{2} \mathrm{SO}_{4}\right)($ Catalogue \#109073, Merck) was then added to the sample. The formation of green/blue color indicates the presence of steroid while red/orange sediment indicates the presence of triterpenoid. ${ }^{9-11}$

\section{Terpenoid Identification}

A mixture of $10 \mathrm{mg} \mathrm{SPE}$ and vanilin in a spot plate were added with one drop of absolute $\mathrm{H}_{2} \mathrm{SO}_{4}$. The violet colour formation indicate the presence of terpenoid compound in plant extract. ${ }^{9-11}$

\section{Quantitative Analysis/Liquid Chromatography} Electrospray Ionization Tandem Mass Spectrometric (LCESI-MS)

Quantitative Analysis/LC-ESI-MS was performed to measure the content of rutin, chlorogenic acid, and caffeic acid in SPE using method previously described. ${ }^{10}$ The chromatographic separation was performed on high performance liquid chromatography (HPLC) Accela 1250 Pump (Thermo Scientific, Massachusetts, USA). The samples were dissolved in $1 \mathrm{~mL}$ methanol gradient grade and filtered through $0.2 \mu \mathrm{m}$ syringe. Formic acid $0.1 \%$ was used as mobile phase. The samples were injected and separated in hypersil gold coloumn $(50 \mathrm{~mm} \times 2.1$ $\mathrm{mm} \times 1.9 \mu \mathrm{m})$ (Thermo Scientific). MS detection was performed using spectrometer TSQ Quantum Access MAX (Thermo Scientific) with ESI condition: spray voltage $3 \mathrm{kV}$; vaporization temperature $250^{\circ} \mathrm{C}$; capiller temperature $300^{\circ} \mathrm{C}$; sheath gas pressure (nitrogen) $40 \mathrm{psi}$; and aux gas pressure (argon) 10 psi. The experiment was conducted triplicate for each standard solutions and samples. The analytes were identified by comparing retention time and $\mathrm{m} / \mathrm{z}$ values obtained by MS with the mass spectra from corresponding standards tested under the same conditions. $^{10}$

\section{Validation Method}

Quantitative analysis method was validated by calculating its linearity, limit of detection (LOD) and limit of quantification (LOQ). The standard compound rutin (Catalogue \#BP1234, Chengdu Biopurify Phytochemicals, Chengdu, China) chlorogenic acid (Catalogue \#BP0345, Chengdu Biopurify Phytochemicals), caffeic acid (Catalogue\#BP0300, Chengdu Biopurify Phytochemicals) were prepared. Each standard compounds were dilluted at following concentration: 0.1, $0.3,1.0$, and $2.0 \mu \mathrm{g} / \mathrm{mL}$. Standard solution regression equations were then calculated. The LOD and LOQ were determined at signal-to-noise $(\mathrm{S} / \mathrm{N})$, respectively. ${ }^{10}$

\section{Molecular Docking}

The binding conformation of phytochemical compound found in SPE towards protein related in skin aging process was modeled using molecular docking. The crystallographydrived structure data of matrix metalloproteinase (MMP)-1 were retrieved from RCSB protein data bank, with PDBID 2Y9X. The receptor data was then prepared by removing crystallographic water and removing any co-crystallized ligand found. Molecular docking was performed using AutoDock Vina (The Scripps Research Institute, La Jolla, USA) under default configuration. ${ }^{12}$ Best conformation generated was used in the visual analysis using UCSF Chimera. ${ }^{13}$ The method was validated by redocking of co-crystallized ligand (N-hydroxy-2-[4-(4-phenoxybenzenesulfonyl)-tetrahydro-pyran-4-yl]-acetamide) to its respective protein. Then the root-mean-square deviation (RMSD) of crystal conformation and docked conformation was calculated.

\section{Results}

\section{Qualitative Phytochemical Screening}

Qualitative phytochemical screening was done to assess the phytochemical constituent found in SPE. The result of SPE phytochemical screening can be seen in (Table 1). The screening showed that SPE contained phytochemicals compound which belonged to flavonoid, tannin, phenol, triterpenoid, saponin and alkaloid. While the presence of steroid and terpenoid was expected to be none.

Table 1. Qualitative phytochemical screening of SPE.

\begin{tabular}{|c|c|}
\hline Phytochemicals & Result \\
\hline Flavonoid & + \\
\hline Saponin & + \\
\hline Phenol & + \\
\hline Tanin & + \\
\hline Steroid/Triterpenoid & $-/+$ \\
\hline Terpenoid & - \\
\hline Alkaloid & + \\
\hline
\end{tabular}




\section{LC-ESI-MS}

In the present work, the quantitative analysis (LC-ESI-MS) of phenolic and polyphenolic compounds present in SPE were evaluated (Figure 1). The analysis of SPE detected a a peak resembles to chlorogenic acid (MS 179) standard as shown in chromatogram (Figure 1). While peaks resembles to of caffeic acid (MS 353) and rutin (MS 609) cannot be found in SPE. Thus, based on the analysis only chlorogenic acid was present in SPE whilst rutin and caffeic acid were not detected. Quantitative analysis was then performed (Table 2). The SPE was contained chlorogenic acid around $1.073 \mathrm{mg} / \mathrm{g}$ dry weight. While rutin and caffeic acid was below the LOD.

\section{Molecular Docking}

Molecular docking was performed to model the possible binding conformation of chlorogenic acid toward MMP-
1. The validation of the docking method was done using redocking the bound compound found in protein data to the respective protein and calculating the RMSD of crystal conformation and docked conformation. The calculated RMSD of crystal conformation and docked conformation was less than the known cut off $(<2 \AA)$. Thus the molecular docking method used was reasonable and continued with phytochemicals used in present study. The molecular docking was performed triplicate under defaut exhaustiveness settings $(\mathrm{n}=8)$. All compound was successfully docked to the receptor. The binding affinity was retrieved and compared to each other (Table 3). Chlorogenic acid has the highest binding affinity towards MMP-1 (-9.4 kcal/mol). The binding conformation with highest binding affinity was then visualized (Figure 2). Visualization analysis showed that all the potential compound was occupied the active site of the receptor,
$1 \mathrm{~A}$

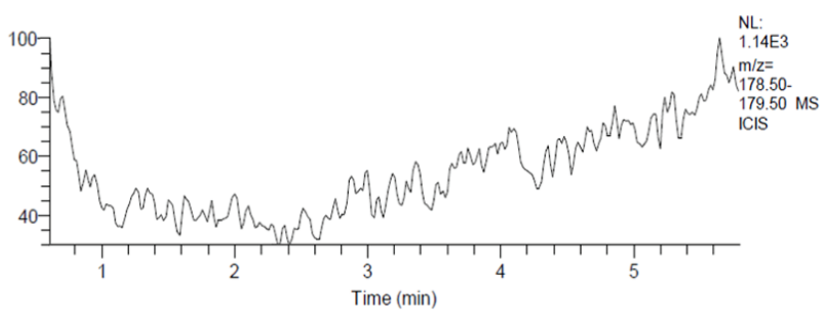

$2 \mathrm{~A}$

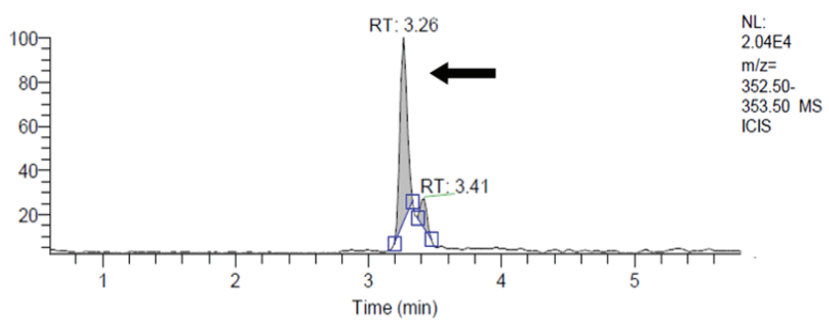

$3 \mathrm{~A}$

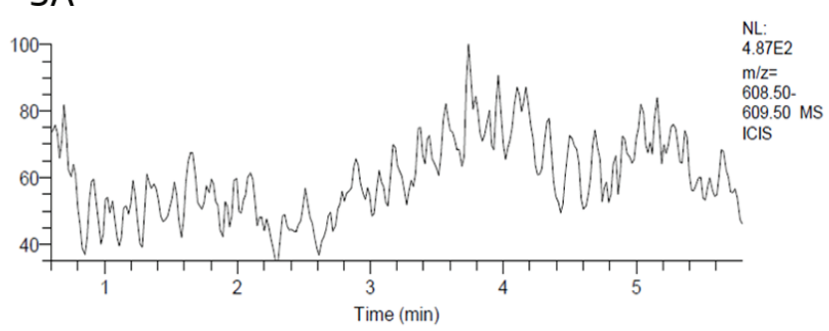

$1 \mathrm{~B}$

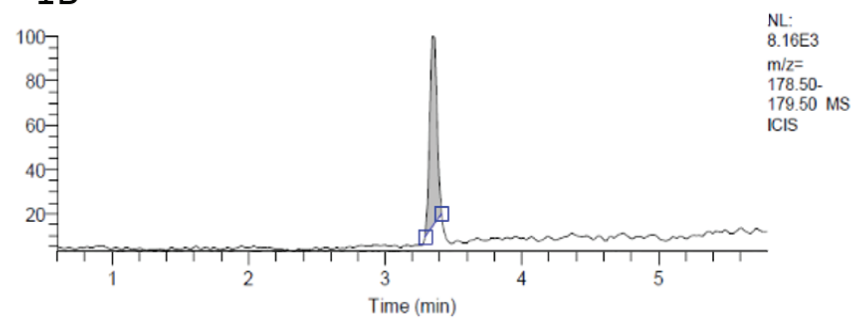

2B

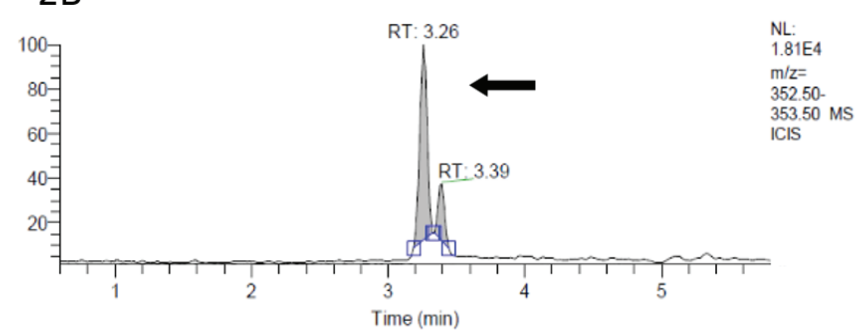

3B

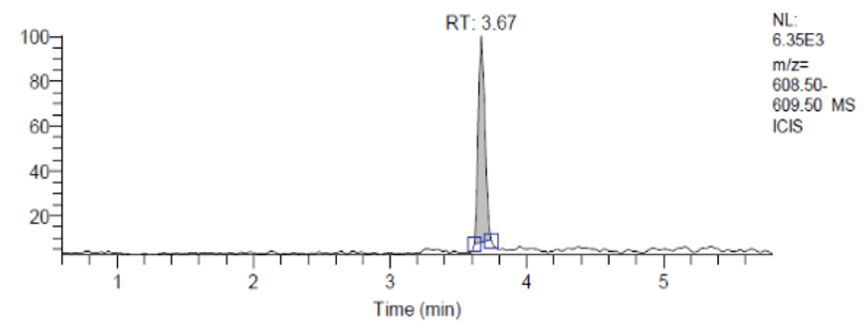

Figure 1. Chromatogram of SPE and standard compound from LC-ESI-MS. The first row showed the comparison of SPE (1A) and caffeic acid (1B); The second row showed the comparison of SPE (2A) and chlorogenic acid (2B); The last row showed the comparison of SPE (3A) and rutin (3B). Chlorogenic acid was present in SPE which indicated by the similar peak with cholorgenic acid standard. 
Table 2. LC-ESI-MS of snake fruit peel extract, rutin, chlorogenic acid, and caffeic acid.

\begin{tabular}{lcccc}
\hline \multicolumn{1}{c}{ Compounds } & $\begin{array}{c}\text { Weight } \\
(\mathbf{g})\end{array}$ & Area & $\begin{array}{c}\text { Measured-Content } \\
(\boldsymbol{\mu g} / \mathbf{m L})\end{array}$ & $\begin{array}{c}\text { Calculated-Content } \\
(\boldsymbol{\mu g} / \mathbf{g})\end{array}$ \\
\hline Caffeic Acid & 0.1 & ND & $<$ LOD & $<$ LOQ \\
Chlorogenic Acid & 0.1 & 63.92 & 1.0733 & 1.073 \\
Rutin & 0.1 & ND & $<$ LOD & $<$ LOQ \\
\hline
\end{tabular}

similar to the bound ligand. The cholorgenic acid shared similar interaction with bound ligand on Ala182.

\section{Discussion}

The qualitative phytochemical screening was showed the presence of several important phytochemical in SPE, especially phenolic acid and polyphenolic compound. Both were commonly found normal human diet and ingested in large quantity compared with other phytochemical compound. ${ }^{14,15}$ Previous study showed similar result with current finding, where snakefruit peel was contained phenolic acid, flavonoid, and tanin. ${ }^{16}$ Phenolic acid and flavonoid are considered as an important antioxidant compound. Flavonoids compounds are characterized by the presence of one or more phenol groups in their structure. This structure enabled phenolic acid and flavonoids to donate its hydrogen atoms, reducing the radical onto its neutral form. ${ }^{17}$ Flavonoid has huge impact in human health. In vitro studies showed flavonoid have wide range of biological activity antioxidant, antiinflammatory anti-microbial, antifungal, antiviral, and anticancer. $^{15,18}$

Apparently, consumption of flavonoids was found to be related to the slowing down of aging process. ${ }^{19}$ This was based on the ability of antioxidants to trigger cell proliferation playing a close role in regenerating damaged tissue. ${ }^{20}$ Another flavonoid found in large amounts in tea,

Table 3. Binding affinity of docked snake fruit peel phytochemicals compound.

\begin{tabular}{lc}
\hline Compound & $\begin{array}{c}\text { Binding Affinity } \\
\text { (kcal/mol) }\end{array}$ \\
\hline Chlorogenic Acid & -9.4 \\
Bound Ligand & -9.9 \\
\hline
\end{tabular}

epicathecin, was able to protect fibroblast cells from ROS and subsequently apoptosis. ${ }^{4,21}$ The administration of plant extracts was also known to be able to strongly inhibit the degradation activity of elastase and also maintained the skin elastase. ${ }^{9,22}$ This also supports the potential of flavonoid to play a role in maintaining skin elasticity due to its antioxidant activity.

The quantitative analysis of several phenolic acid and flavonoids was showed SPE contained chlorogenic acid. Chlorogenic acid is an ester of quinic acid and caffeic acid. Chlorogenic acid is an important biologically active dietary polyphenol and major compound found in coffee (Coffea arabica). Numerous evidence has demonstrated that chlorogenic acid is known for many biological activities: including anti-carcinogenic, antiinflammatory, and antioxidant properties. ${ }^{23}$ Previous study showed the consumption of food rich in chlorogenic acid was correlated with low facial hyperpigmentation in Japanese middle-aged females. The study speculated that polyphenols, including chlorogenic acids, may helps protect human skin from photoaging and contribute to the decreased hyper-pigmentation of pigmented spots. ${ }^{24}$

To further investigate possible interaction between phytochemicals found in SPE towards enzyme related in aging process previously described, molecular docking was performed. Molecular docking of phytochemicals found chlorogenic acid was a potential binder towards MMP-1. Visual analysis showed that docked compound reside the active site cavity of the respective protein. Thus present study proposed the possible binding conformation of chlorogenic acid towards MMP-1.

\section{Conclusion}

Chemical constituents of SPE and its in silico anti-aging potency were evaluated. Current findings may provide scientific evidence for possible usage of SPE and its compounds as antioxidant and anti-aging agent. 


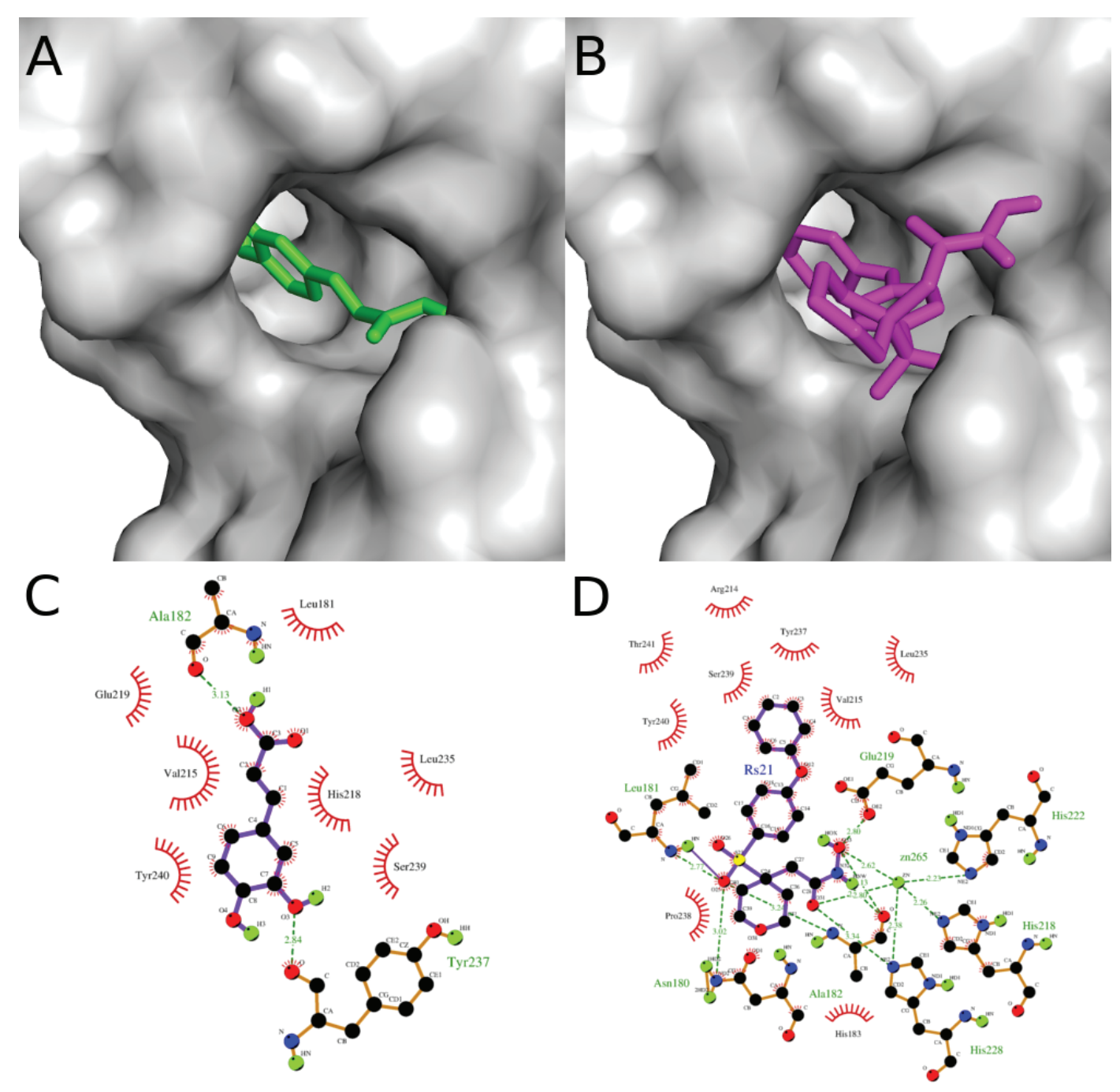

Figure 2. Molecular docking of phytochemical compounds against MMP1 chlorogenic acid and N-hydroxy-2-[4(4-phenoxy-benzenesulfonyl)-tetrahydro-pyran-4-yl]-acetamide towards MMP1. A,B: the protein showed as surface representation with The ligand showed as stick representation with only polar hydrogen showed. Both compound occupied the active site of the receptor; C,D: the receptor ligand interaction presented in intermolecular diagram. The cholorgenic acid shared similar interaction with bound ligand on Ala182.

\section{Acknowledgements}

The authors gratefully acknowledge the financial support from Universitas Prima Indonesia, Medan.This research was also supported by Biomolecular and Biomedical Research Center, Aretha Medika Utama, Bandung, West Java, Indonesia by providing the laboratory facilities and research methodology. We are thankful to Rismawati Laila Qodariah, Wisma Ni Luh Ekayanti, Wahyu Setya Widodo, Annisa Amalia, Hanna Sari W. Kusuma from the Biomolecular and Biomedical Research Center, Aretha Medika Utama, Bandung, West Java, Indonesia, for their valuable assistance

\section{References}

1. Farage MA, Miller KW, Elsner P, Maibach HI. Characteristics of the aging skin. Adv Wound Care. 2013; 2(1): 5-10.

2. Farage MA, Miller KW, Elsner P, Maibach HI. Intrinsic and extrinsic factors in skin ageing: a review. Int J Cosmet Sci. 2008; 30(2): 8795.

3. Davalli P, Mitic T, Caporali A, Lauriola A, D’Arca D. ROS, cell senescence, and novel molecular mechanisms in aging and agerelated diseases. Oxid Med Cell Longev. 2016; 2016: 3565127. doi: $10.1155 / 2016 / 3565127$

4. Tanigawa T, Kanazawa S, Ichibori R, Fujiwara T, Magome T, Shingaki $\mathrm{K}$, et al. (+)-Catechin protects dermal fibroblasts against oxidative stress-induced apoptosis. BMC Complement Altern Med. 2014; 14(1): 133. doi: 10.1186/1472-6882-14-133. 
5. Dias DA, Urban S, Roessner U. A historical overview of natural products in drug discovery. Metabolites. 2012; 2(2): 303-36.

6. Evacuasiany E, Ratnawati H, Liana L, Widowati W, Maesaroh M, Mozef T, et al. Cytotoxic and antioxidant activities of catechins in inhibiting the malignancy of breast cancer. Oxid Antioxid Med Sci. 2014; 3(2): 141-6.

7. Nijveldt RJ, van Nood E, van Hoorn DE, Boelens PG, van Norren K, van Leeuwen PA. Flavonoids: a review of probable mechanisms of action and potential applications. Am J Clin Nutr. 2001; 74(4): 41825.

8. Rusmana D, Wahyudianingsih R, Elisabeth M, Balqis B, Maesaroh M, Widowati W. Antioxidant activity of Phyllanthus niruri extract, rutin and quercetin. Indones Biomed J. 2017; 9(2): 84-90.

9. Widowati W, Fauziah N, Herdiman H, Afni M, Afifah E, Kusuma HSW, et al. Antioxidant and anti aging assays of Oryza sativa extracts, vanillin and coumaric acid. J Nat Remedies. 2016; 16(3): 88-99.

10. Widowati W, Rani AP, Hamzah RA, Arumwardana S, Afifah E, Kusuma HSW, et al. Antioxidant and antiaging assays of Hibiscus sabdariffa extract and its compounds. Nat Prod Sci. 2017; 23(3): 192-200.

11. Widowati W, B WJ, Nadya S, Amalia A, Arumwardana S, Kusuma HSW, et al. Antioxidant and antiaging activities of Jasminum sambac extract, and its compounds. J Reports Pharm Sci. 2018; 7(3): 270-85.

12. Trott $\mathrm{O}$, Olson AJ. AutoDock Vina: Improving the speed and accuracy of docking with a new scoring function, efficient optimization, and multithreading. J Comput Chem [Internet]. 2010; 31(2): 455-61.

13. Pettersen EF, Goddard TD, Huang CC, Couch GS, Greenblatt DM, Meng EC, et al. UCSF Chimera-A visualization system for exploratory research and analysis. J Comput Chem. 2004; 25(13): 1605-12.

14. Chun OK, Chung SJ, Song WO. Estimated dietary flavonoid intake and major food sources of U.S. Adults. J Nutr. 2007; 137(5): 124452.

15. Lotito S, Frei B. Consumption of flavonoid-rich foods and increased plasma antioxidant capacity in humans: Cause, consequence, or epiphenomenon? Free Radic Biol Med. 2006; 41(12): 1727-46

16. Suica-Bunghez IR, Teodorescu S, Dulama ID, Voinea OC, Imionescu S, Ion RM. Antioxidant activity and phytochemical compounds of snake fruit (Salacca Zalacca). IOP Conf Ser Mater Sci Eng [Internet] 2016; 133: 012051. doi: 10.1088/1757-899X/133/1/012051.

17. Cetinkaya H, Kulak M, Karaman M, Karaman HS, Kocer F. Flavonoid accumulation behavior in response to the abiotic stress: can a uniform mechanism be illustrated for all plants? In: Flavonoids From Biosynthesis to Human Health. London: InTech Open; 2017.

18. Hoensch HP, Oertel R. The value of flavonoids for the human nutrition: Short review and perspectives. Clin Nutr Exp. 2015; 3 : 8-14.

19. Prasain JK, Carlson SH, Wyss JM. Flavonoids and age-related disease: Risk, benefits and critical windows. Maturitas. 2010; 66(2): 163-71.

20. Pallardó FV, Markovic J, García JL, Viña J. Role of nuclear glutathione as a key regulator of cell proliferation. Mol Aspects Med. 2009; 30(1-2): 77-85.

21. Widowati W, Widyanto RM, Husin W, Ratnawati H, Laksmitawati $\mathrm{DR}$, Setiawan B, et al. Green tea extract protects endothelial progenitor cells from oxidative insult through reduction of intracellular reactive oxygen species activity. Iran J Basic Med Sci. 2014; 17(9): 702-9.

22. Tsukahara K, Nakagawa H, Moriwaki S, Takema Y, Fujimura T, Imokawa G. Inhibition of ultraviolet-B-induced wrinkle formation by an elastase-inhibiting herbal extract: implication for the mechanism underlying elastase-associated wrinkles. Int J Dermatol. 2006; 45(4): 460-8

23. Tajik N, Tajik M, Mack I, Enck P. The potential effects of chlorogenic acid, the main phenolic components in coffee, on health: a comprehensive review of the literature. Eur J Nutr. 2017; 56(7): 2215-44.

24. Fukushima Y, Takahashi Y, Hori Y, Kishimoto Y, Shiga K, Tanaka $\mathrm{Y}$, et al. Skin photoprotection and consumption of coffee and polyphenols in healthy middle-aged Japanese females. Int $\mathrm{J}$ Dermatol. 2015; 54(4): 410-8. 